\title{
Effect of annealing time on aluminum-induced crystallization of silicon suboxide thin films
}

\author{
Alexandr Zamchiy ${ }^{1,2^{*}}$, Evgeniy Baranov ${ }^{1}$, Sergey $\mathrm{Khmel}^{1}$, and Marat Sharafutdinov ${ }^{3}$ \\ ${ }^{1}$ Kutateladze Institute of Thermophysics SB RAS, 630090 Novosibirsk, Russia \\ ${ }^{2}$ Novosibirsk State University, 630090, Novosibirsk, Russia \\ ${ }^{3}$ Institute of Solid State Chemistry and Mechanochemistry SB RAS, 630128 Novosibirsk, Russia
}

\begin{abstract}
Polycrystalline silicon (poly-Si) thin films were obtained by aluminium induced crystallisation of amorphous silicon suboxide $\left(\mathrm{a}-\mathrm{SiO}_{\mathrm{x}}\right.$, $\mathrm{x}=0.22$ ) via annealing of $\mathrm{a}-\mathrm{SiO}_{0.22} / \mathrm{Al}$ bilayer structures at $550{ }^{\circ} \mathrm{C}$ for $4-$ $30 \mathrm{~h}$. The a-SiO $\mathrm{S}_{0.22} / \mathrm{Al}$ thickness ratio was approximately 1 . According optical microscopy measurements, the crystallized fraction reached the saturation value of $85 \%$ after annealing for $20 \mathrm{~h}$. The further increase in the annealing time didn't lead to an increase in this value. X-ray diffraction measurements revealed that the formed poly-Si had a strong $\mathrm{Si}$ (111) preferred orientation.
\end{abstract}

\section{Introduction}

The fabrication of large-grained polycrystalline silicon (poly-Si) thin films with large grains on foreign cheap substrates (e.g. glass) is of considerable interest for thin-film transistors and silicon solar cells technologies [1]. The preparation of poly-Si thin films on glass substrates is carried out in two stages. The first stage involves the synthesis of the amorphous silicon ( $\mathrm{a}-\mathrm{Si}$ ) layers and then, in a second stage, a-Si is subjected to conventional solid phase crystallization (SPC), metal-induced crystallization (MIC) or liquid-phase crystallization (LIC) [2]. By the present time, having quite important advantages over other techniques, aluminium-induced crystallization (AIC), the particular case of MIC, seems the most prospective way of thin poly-Si films fabrication on glass [3]. The crystallization of a-Si by AIC implies thermal annealing of a-Si/Al layers below the eutectic temperature of the $\mathrm{Si}-\mathrm{Al}$ system $\left(577^{\circ} \mathrm{C}\right)$ as a result of which aluminium-induced layer exchange mechanism (ALILE) takes a place [4]. Aluminum oxide $\left(\mathrm{AlO}_{\mathrm{x}}\right)$ interfacial layer plays an important role in ALILE [5]. Acting as a permeable membrane, this layer controls the flux of $\mathrm{Si}$ atoms into the $\mathrm{Al}$ film, determining the kinetics of $\mathrm{AIC}$. The $\mathrm{AlO}_{\mathrm{x}}$ layer is intentionally prepared before the deposition of a-Si film by holding the deposited Al layer for several tens of hours in air ambient [1].

In this paper, amorphous silicon suboxide $\left(\mathrm{a}-\mathrm{SiO}_{\mathrm{x}}, 0<\mathrm{x}<2\right)$ is used instead of a-Si as a silicon source in AIC which allows eliminating the technological step associated with the formation of $\mathrm{AlO}_{\mathrm{x}}$ layer [5]. The impact of annealing time on the $\mathrm{AIC}$ of $\mathrm{a}-\mathrm{SiO}_{\mathrm{x}}$ is analyzed.

\footnotetext{
*Corresponding author: zamchiy@gmail.com
} 


\section{Experimental details}

At first, Corning Eagle XG glass substrates were ultrasonicated in an aqueous solution of sodium dodecyl sulfate surfactant, acetone, DI water, and dried using a nitrogen gun. Then, the initial Al layers $220 \mathrm{~nm}$ thick were deposited at room temperature using sputtering with Ar plasma. Subsequently, without Al sample exposure to air, Al-coated substrates were transferred into vacuum chamber for $\mathrm{a}-\mathrm{SiO}_{\mathrm{x}}$ thin films deposition by the gas-jet electron beam plasma chemical vapor deposition method [6]. The thickness of $\mathrm{a}-\mathrm{SiO}_{\mathrm{x}}$ thin films coated onto the $\mathrm{Al}$ layers was $\sim 220 \mathrm{~nm}$. Thus, the a-SiO${ }_{0.22} / \mathrm{Al}$ thickness ratio was approximately 1 . Thicknesses of $\mathrm{Al}$ and $\mathrm{a}-\mathrm{SiO}_{\mathrm{x}}$ were measured by transmission electron microscopy using a JEOL $4000 \mathrm{EX}$ microscope operated at $400 \mathrm{kV}$ [7]. Fourier transform infrared (FTIR) spectrometry was used for the investigation of the composition (bonded oxygen and hydrogen atomic concentration) and the bond structure of as-deposited film obtained on crystalline silicon wafer. Bruker IFS-113V Fourier spectrometer was used for the recording of FTIR spectra in the wavenumber range of $400-4000 \mathrm{~cm}^{-1}$ with a $1 \mathrm{~cm}^{-1}$ resolution. The procedure used for obtaining of the concentration of bonded hydrogen and oxygen is described in [8]. After the $\mathrm{Al}$ and $\mathrm{a}-\mathrm{SiO}_{\mathrm{x}}$ layers deposition, the layer structure was annealed in furnace (Nabertherm RHTC 80-710/15) at $550^{\circ} \mathrm{C}$ in vacuum for duration of 2-30 hours. During the heating process, the heating rate was kept constant $-5{ }^{\circ} \mathrm{C} / \mathrm{min}$. Also during the heating, the samples were annealed at $400{ }^{\circ} \mathrm{C}$ for $30 \mathrm{~min}$ for slow and nondestructive effusion of bonded hydrogen from the $\mathrm{a}-\mathrm{SiO}_{\mathrm{x}}$ thin films. Optical microscope (OM) OLYMPUS BX51M was used for the investigation of the surface morphology of the samples including the continuity of formed poly-Si thin films. X-ray diffraction (XRD) was used to characterization of the crystalline properties of the samples. XRD patterns were obtained using time resolved diffractometry station (channel 5b, VEPP-3) of the Siberian Synchrotron and Terahertz Radiation Center [9]. An OD-3M position-sensitive detector was used in the conventional experimental setup with a wavelength $1.516 \AA$. The detector was positioned at an angle of $25^{\circ}-56^{\circ}$ to record the main silicon peaks. The acquisition time was $20 \mathrm{~min}$. After intensity normalization, the signal of the empty substrate was eliminated from the signal of the sample. After annealing, the formed Al-matrix was etched by a standard etching solution $(80 \%$ of phosphoric acid $+5 \%$ of nitric acid $+5 \%$ of acetic acid $+10 \%$ of DI water) at $50{ }^{\circ} \mathrm{C}$ for $20 \mathrm{~min}$ [3].

\section{Results and discussion}

According to FTIR spectroscopy, as-deposited $\mathrm{a}_{-} \mathrm{SiO}_{\mathrm{x}}$ films contain $\sim 18$ at.\% (stoichiometric coefficient $\mathrm{x}=0.22$ ) and $\sim 4$ at.\% bonded oxygen and hydrogen, respectively.

Fig. 1 shows OM images of the glass/Al interface after annealing at $550{ }^{\circ} \mathrm{C}$ for $4 \mathrm{~h}(\mathrm{a}), 8 \mathrm{~h}$ (b), and $30 \mathrm{~h}(\mathrm{c})$.
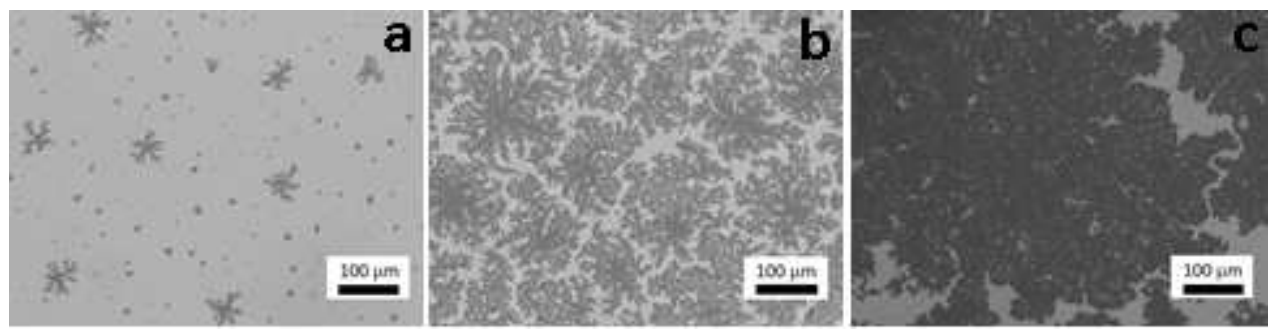

Fig. 1. Optical micrographs of samples after annealing at $550{ }^{\circ} \mathrm{C}$ for (a) $4 \mathrm{~h}$, (b) $8 \mathrm{~h}$, (c) $30 \mathrm{~h}$. 
At the images obtained from the backside of the samples, dark and white areas corresponding to poly-Si and $\mathrm{Al}$, respectively, due to the lower reflectivity of $\mathrm{Si}$ in comparison with Al. During the annealing process, as a result of the interdiffusion of Si and $\mathrm{Al}$ atoms through the barrier layer, which is probably formed at the initial deposition of a-SiO ${ }_{x}$ [5] a supersaturation of $\mathrm{Si}$ in $\mathrm{Al}$ and the formation of Si nuclei occurs. Fig. 1 (a) demonstrates isolated poly-Si regions, which have conventional dendritic structure [4]. With increasing of the annealing time, these poly-Si regions increase in size in all directions in the observed plane and begin to close (Fig. 1 (b)). During the subsequent annealing, poly-Si regions form continuous sections as a result of coalescence (Fig. 1 (c)). However, the formation of a continuous poly-Si film does not occur. Thus, according to the OM images (Fig. 1a-c), one can conclude that during the aluminium-induced annealing of the a$\mathrm{SiO}_{\mathrm{x}}$ thin films, the conventional ALILE process proceeds with its characteristic growth morphology and the evolutionary features of the emerging poly-Si regions [10]. The macroscopic layer exchange as a result of ALILE was confirmed by scanning and transmission electron microscopy investigations of annealed samples cross sections [7].

Crystallized fraction (percentage of the surface covered by poly-Si) versus annealing time of the samples obtained on the basis of OM images is shown in Fig. 2 (a). The Si crystallites first appear on OM photos for the annealing time of $4 \mathrm{~h}$. The curve has a $\mathrm{S}$-shape which is typical for a phase transformation process [10]. As can be seen from Fig. 2 (a), saturation regime of crystallization process begins at $20 \mathrm{~h}$ and the further increase in the annealing time doesn't lead to an increase in the crystallized fraction. Apparently, the formation of a continuous poly-Si film (the saturation value of crystallized fraction equals to 85\%) doesn't occur due to a lack of the sufficient Si content in an asdeposited $\mathrm{a}-\mathrm{SiO}_{0.22}$ film $[4,7 \mathrm{10}$. Thus, an increase in the crystallized fraction and, as a consequence, the fabrication of a continuous poly-Si film is possible by increasing the initial a- $\mathrm{SiO}_{0.22} / \mathrm{Al}$ thickness ratio and/or by increasing $\mathrm{Si}$ content in as-deposited silicon suboxide thin film. But even in the case of a-Si AIC the thickness ratio should not be less than 1 [4].

The crystalline quality of the formed poly-Si was characterized by XRD. Before the XRD analysis of the annealed samples, the top layer (a mixture of aluminum, silicon, and oxygen) [7] was etched off. Etching of the upper layer made it possible to obtain a more intense signal of crystalline silicon in XRD patterns. The XRD pattern of the sample annealed for $30 \mathrm{~h}$ (Fig. 2 (b)) demonstrates a narrow peak centered on $2 \theta=28.4^{\circ}$ ( $\theta$ is the angle of incidence-reflection), which corresponds to crystalline silicon with the (111) plane [11]. Peaks corresponding to other orientations were not observed in the pattern. This picture is typical of all samples annealed for $4 \mathrm{~h}$ and more.
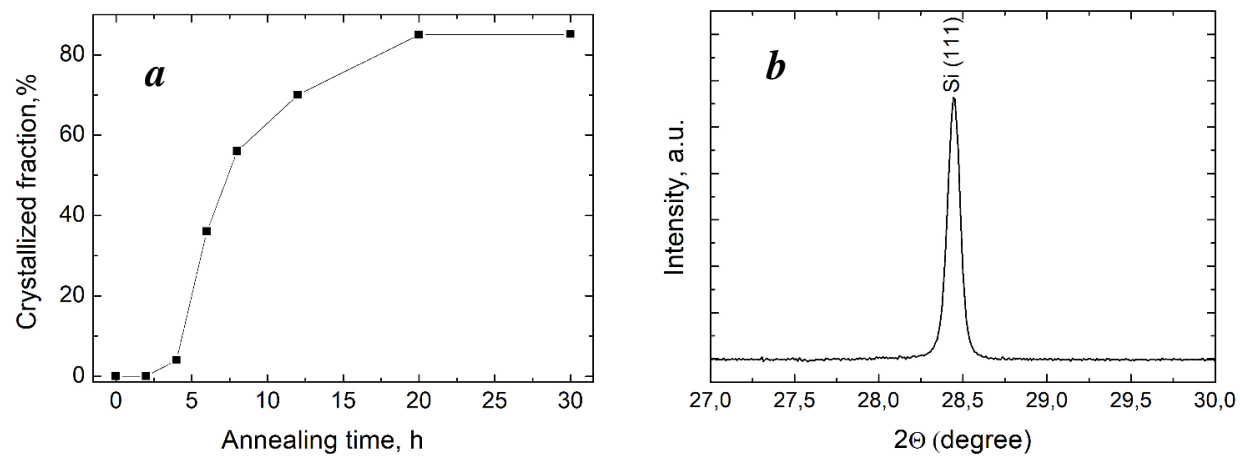

Fig. 2. (a) Crystallized fraction versus annealing time of the samples. (b) XRD pattern of the sample annealed at $550{ }^{\circ} \mathrm{C}$ for $30 \mathrm{~h}$. 


\section{Conclusions}

Poly-Si thin films were obtained by annealing of a-SiO $\mathrm{S}_{0.22} / \mathrm{Al}$ bilayer samples with a thickness ratio of $\sim 1$ at $550{ }^{\circ} \mathrm{C}$ for $4-30 \mathrm{~h}$. According optical microscopy measurements, the crystallized fraction reached the saturation value of $85 \%$ after annealing for $20 \mathrm{~h}$. Further increase in the value is possible due to an increase of an initial thicknesses ratio and/or a decrease in stoichiometry of $\mathrm{a}-\mathrm{SiO}_{\mathrm{x}}$ thin film. XRD measurements revealed that the formed poly-Si had a strong Si (111) preferred orientation.

This study was financially supported by the Russian Science Foundation, project \# 17 79-10352.

The measurements of XRD spectra were done using the infrastructure of the Shared-Use Center "Siberian Synchrotron and Terahertz Radiation Center (SSTRC)" based on VEPP-3/VEPP4M/NovoFEL of BINP SB RAS supported by The Ministry of Education and Science of The Russian Federation (project RFMEFI62117X0012).

\section{References}

1. M. Jung, A. Okada, T. Saito, T. Suemasu, and N. Usami, Appl. Phys. Exp. 3, 095803, (2010).

2. J. Haschke, D. Amkreutz, and B. Rech, Jpn. J. Appl. Phys. 55, 04EA04 (2016).

3. J. Chen, J. Suwardy, T. Subramani, W. Jevasuwan, T. Takei, K. Toko, T. Suemasu and N. Fukata, Cryst. Eng. Comm, 19, 2305, (2017).

4. O. Nast, S.R. Wenham, J. Appl. Phys. 88, 124 (2000).

5. J.-H. Yoon, Phys. Status Solidi RRL 10, 668 (2016).

6. E. Baranov, S. Khmel, A. Zamchiy, M. Buyko, Phys. Status Solidi A, 213, 1783 (2016).

7. A.O. Zamchiy, E.A. Baranov, S.Ya. Khmel, V.A. Volodin, V.I. Vdovin, A.K. Gutakovskii, Appl. Phys. A 124, 646 (2018).

8. E. Baranov, A. Zamchiy, and S. Khmel, Tech. Phys. Lett. 41, 1013 (2015).

9. O.V. Evdokov, V.M. Titov, B.P. Tolochko, M.R. Sharafutdinov, Nucl. Instruments Methods Phys. Res. Sect. A Accel. Spectrometers, Detect. Assoc. Equip. 603, 194 (2009).

10. S. Tutashkonko, N. Usami, Thin Solid Films 616, 213 (2016).

11. A.O. Zamchiy, E.A. Baranov, I.E. Merkulova, V.A. Volodin, M.R. Sharafutdinov, S.Y. Khmel, Vac. 152, 319 (2018). 